Vol. 5, Special Issue 2, April 2017

\title{
Study on Different types of Micro-Inverter
}

\author{
Sudhir Pai ${ }^{1}$, Abhishek PV $^{2}$, Sathyanarayana $\mathbf{P}^{3}$, Sachin K Shetty ${ }^{4}$, Srinidhi $\mathbf{M}^{5}$ \\ 8th Semester, Dept. of Electrical and Electronics, S.D.M. Institute of Technology, Ujire (D.K), Karnataka ${ }^{1,2,4,5}$ \\ Assistant professor, Dept. of Electrical and Electronics, S.D.M. Institute of Technology, Ujire (D.K), Karnataka ${ }^{3}$
}

\begin{abstract}
This paper introduces micro inverters which are presently available in the industry, these micro inverters are looked into their properties which reveal certain characteristics when subjected to certain conditions, by this we are able to select a micro inverter as per our requirement.
\end{abstract}

\section{INTRODUCTION}

Wind and solar PV are currently the fastest-growing sources of electricity globally. In 2015 their additional annual generation met more than $90 \%$ of the incremental demand for electricity [1].

The Solar power has been an advent of engineering in harnessing the sunlight to a more usable form of energy. Presently technology has enabled to convert solar energy to heat and electricity. Research is being conducted toincrease the efficiency of conversion of the solar panels. The conversion of solar power to electricity is a huge application, this is only useful for if the load requirement is DC i.e. Direct Current. For long Distance transmission this DC is to be transformed into AC Supply with a matching frequency and voltage level. For this purpose, a DC/AC converters are used. Now, there are the conventionally used string inverters which converts DC to $\mathrm{AC}$ as a whole and utilised and the other viable option is using a micro inverter.

A micro inverter, is a device used in photovoltaics that converts direct current (DC) generated by a single solar module to alternating current (AC). The output from several micro inverters is combined and often fed to the electrical grid. Micro inverters contrast with conventional string and central solar inverters, which are connected to multiple solar modules or panels of the PV system. Micro inverters have several advantages over conventional inverters. The main advantage is that small amounts of shading, debris or snow lines on any one solar module, or even a complete module failure, do not disproportionately reduce the output of the entire array. Each micro inverter harvests optimum power by performing maximum power point tracking for its connected module. Simplicity in system design, simplified stock management, and added safety are other factors introduced with the micro inverter solution. [2]

More importantly, a micro inverter attached to a single panel allows it to isolate and tune the output of that panel. For example, in the same 10-panel array used as an example above, withmicro inverters any panel that is underperforming has no effect on panels around it. In that case, the array as a whole produces as much as $5 \%$ more power than it would with a string inverter. When shadowing is factored in, if present, these gains can become considerable, with manufacturers generally claiming 5\% better output at a minimum, and up to $25 \%$ better in some cases [3].

\section{ADVANTAGES}

While microinverters generally have a lower efficiency than string inverters, the overall efficiency is increased due to the fact that every inverter / panel unit acts independently.

In a string configuration, when a panel on a string is shaded, the output of the entire string of panels is reduced to the output of the lowest producing panel. This is not the case with micro inverters.

A further advantage is found in the panel output quality. The rated output of any two panels in the same production run can vary by as much as $10 \%$ or more. This is mitigated with a string configuration but not so in a micro inverter configuration. The result is maximum power harvesting from a micro inverter array.

Monitoring and maintenance is also easier as many micro inverter producers provide apps or units [4].

\section{DISADVANTAGE}

The main disadvantage of the microinverter concept has, until recently, been cost. Because each microinverter has to duplicate much of the complexity of a string inverter but spread that out over a smaller power rating, costs on a per-watt basis is greater. This offsets any advantage in terms of simplification of individual components Like string inverters, economic considerations force manufacturers to limit the number of models they produce. Most produce a single model that may be over or undersize when matched with a specific

panel. In many cases the packaging can have a significant effect on price. With a central inverter you may have only one set of panel connections for dozens of panels, a single 
AC output, and one box. With microinverters, each one - Inversion

has to have its own set of inputs and outputs, in its own - Maximum power point tracking

box. Because that box is on the roof, it has to be sealed and weatherproofed. This can represent a significant portion of the overall price-per-watt.

To further reduce costs, some models control two or three panels from a single box, reducing the packaging and associate costs. Some systems simplyplace two entire micros in a single box, while others duplicate onlytheMPPT section of the system and use a single DCto-AC stage for further cost reductions. Some have suggested that this approach will make micro inverters comparable in cost with those using string inverters [5]. With steadily

decreasing prices, the introduction of dual micro inverters and the advent of wider [6] model selections to match PV module output more closely, cost is less of an obstacle so micro inverters may now spread more widely.

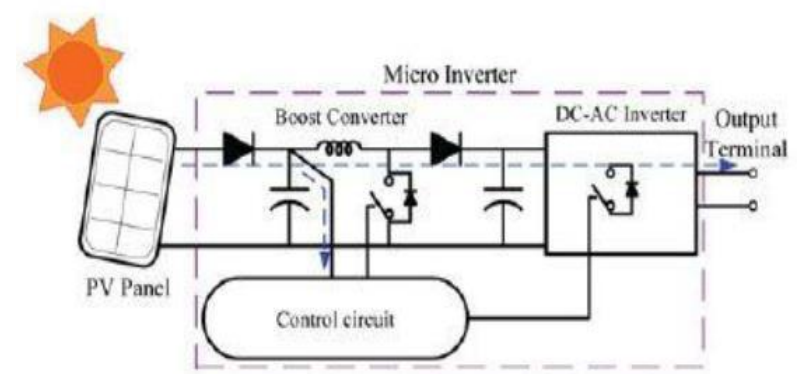

Fig.1. micro inverter block diagram

\section{TYPES OF CONVERTERS}

(1) Buck converter

(2) Boost converter

(3) Buck-boost converter

Buck converter: the step-down or the buck converter as the name suggests, gives an output voltage that is always smaller than the input voltage.

Step-up or boost converter: the boost converter as the name suggests, gives an output voltage that is higher than the input voltage.

Buck-boost converter: the buck boost converter gives an output voltage that can be either higher or lower than the input voltage depending on the operating duty ratio.

\section{V.KEY INVERTER FUNCTIONS}

In the case of grid-tied PV, the inverter is the only piece of electronics needed between the array and the grid. Off-grid PV applications use an additional $\mathrm{dc}$ to $\mathrm{dc}$ converter between the array and batteries and an inverter with a built-in charger. Two major functions or features are common to all transformer-based, grid-tied inverters:
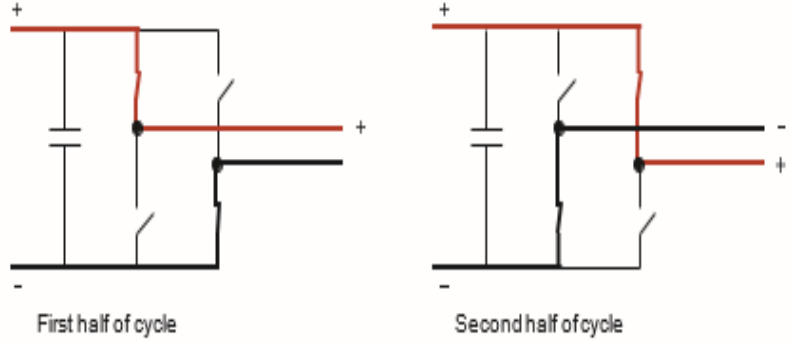

Fig .2. An H-bridge circuit performs the basic conversion from dc to ac power

An important reason that ac won out is because it can be stepped up and travel long distances with low losses and with minimal material. This could change in the distant future if more of our energy is produced, stored and consumed by means of dc power. Today, the technology exists to boost dc electricity to high voltages for long distance transfer, but it is very complex and costly.

For the foreseeable future, ac will carry electricity between our power plants, cities, homes and businesses. In an inverter, dc power from the PV array is inverted to ac power via a set of solid state switches-MOSFETs or IGBTs - that essentially flip the dc power back and forth, creating ac power. Diagram 1 shows basic H-bridge operation in a single-phase inverter.

\section{Maximum power point tracking.}

The method an inverter uses to remain on the ever-moving maximum power point (MPP) of a PV array is called maximum power point tracking (MPPT). PV modules have a characteristic I-V curve that includes a short-circuit current value (Isc) at $0 \mathrm{Vdc}$, an open-circuit voltage (Voc) value at $0 \mathrm{~A}$ and a "knee" at the point the MPP is foundthe location on the I-V curve where the voltage multiplied by the current yields the highest value, the maximum power. Diagram 2 shows the MPP for a module at full sun in a variety of temperature conditions. As cell temperature increases, voltage decreases. Module performance is also irradiance dependent. When the sun is brighter, module current is higher; and when there is less light, module current is lower. Since sunlight intensity and cell 
temperature vary substantially throughout the day and the year, array MPP current and voltage also move significantly, greatly affecting inverter and system design. Efficient conversion of DC power to $\mathrm{AC}$ requires the inverter to store energy from the panel while the grid's AC voltage is near zero, and then release it again when it rises. This requires considerable amounts of energy storage in a small package. The lowest-cost option for the required amount of storage is the electrolytic capacitor, but these have relatively short lifetimes normally measured in years, and those lifetimes are shorter when operated hot, like on a rooftop solar panel. This has led to considerable development effort on the part of microinverter developers, who have introduced a variety of conversion topologies with lowered storage requirements, some using the much less capable but far longer lived film capacitors where possible.

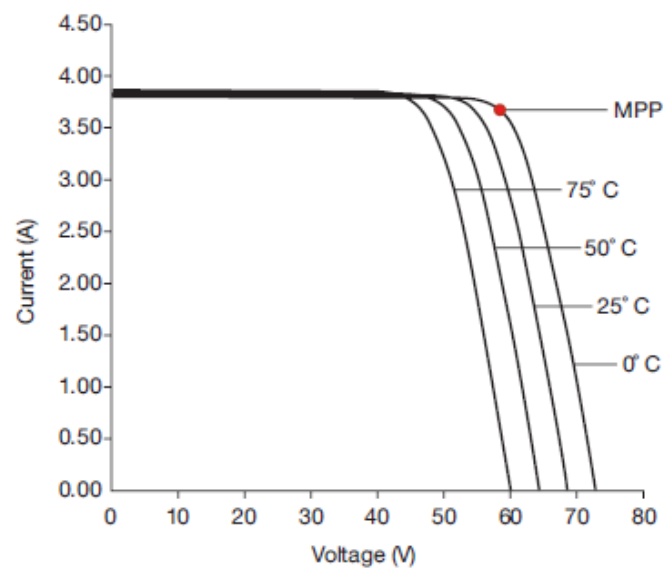

Fig.3. I-V characteristics of a pv module.

Three-phase electric power represents another solution to the problem. In a three-phase circuit, the power does not vary between (say) +120 to -120 Volts between two lines, but instead varies between 60 and +120 or -60 and-120V, and the periods of variation are much shorter. Inverters designed to operate on three phase systems requiremuch less storage. [6][7] A three-phase micro using zero-voltage switching can also offer higher circuit density and lower cost components, while improving conversion efficiency to over $98 \%$, better than the typical one phase peak around 96\%. [8] Three-phase systems, however, are generally only seen in industrial and commercial settings. These markets normally install larger arrays, where price sensitivity is the highest. Uptake of three-phase micros, in spite of any theoretical advantages, appears to be very low.

\section{Competitive landscape and key vendors}

This market is highly competitive and is characterized by the presence of well diversified international and regional providers. The vendors that have high penetration across the US and have plans to expand their operations into Asia Pacific and Europe, middle East and Africa will gain a competitive edge over their peers.

The key vendors in this market are

ABB

Enphase Energy

SMA

SolarEdge

SunPower

Other prominent vendors analysed in this market are APS, Chilicon Power, CyboEnergy, iEnergy, Involar, LeadSolar, ReneSola, and Sparq Systems. [9]

\section{SUMMARY}

Micro inverters are small inverters rated to handle the output of a single panel. micro inverters generally have a lower efficiency than string inverters, the overall efficiency is increased due to the fact that every inverter panel unit acts independently when a panel on a string is shaded the output of theentire string of panels is reduced to the output of the lowestproducing panel. This is not the case with micro inverters. Inversion and maximum power point tracking are main key inverter functions and the main venders of solar microinverter all over the world are ABB, SUNPOWER and ENPHASE ENERGY.

\section{REFERENCES}

[1] NEXT-GENERATION WIND AND SOLAR POWER, FROM COST TO VALUE @OCCED/IEA, OCT 2016.

[2] Market and Technology Competition Increases as Solar Inverter Demand Peaks Greentech Media Staff from GTM Research. Greentech Media, USrs, 26 May 2009. Retrieved on 4 April 2012.

[3] "Enphase Microinverter M190", Enphase Energy

[4] "Enecsys-Monitoring"

[5] SolarBridge and PV Microinverter Reliability, Wesoff, Eric.Greentech Media, US, 2 June 2011.

[6] Li, QuAN; P. Wolfs (2008). "A REVIEW OF THE SinglePhase Photovoltaic Module InTEgRATEd CONVERTER TOPOlOGIES WITH THREE DIFFERENT DC LINK CONFIGURATIONS". IEEE TRANS. ON POWER ELECTRONICS. 23 (3): 1320-1333.

[7] CHEN, LIN; A. AMIRAHMADI; Q. ZHANG; N. KUTKUT;I.BATARSEH."DESIGN AND IMPLEMENTATION OF THREEPHASE TWO-STAGE GRID-CONNECTED MODULE INTEGRATED CONVERTER".IEEE TRANSACTIONS ON POWER ELECTRONICS.

[8] Amirahmadi, AhmadreZa; H. Hu; A. Grishina; Q. Zhang; L. CHEN; U. SOMANI; I. BATARSEH (2014). "ZVS BCM CURRENT CONTROLlED THREE-PHASE MICRO-INVERTER”. IEEE TRANSACTIONS ON POWER ELECTRONICS. 29 (4): 2124-2134.

[9] HTTP://WWW.TECHNAVIO.COM/REPORT/SOLAR

\section{BIOGRAPHIES}

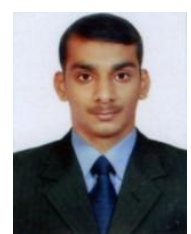

Mr. Sudhir Pai currently pursuing Bachelor of Engineering in Electrical and Electronics at SDM Institute of Technology, Ujire. 
National Conference on Advances in Electrical Engineering NMAM Institute of Technology, Nitte

Vol. 5, Special Issue 2, April 2017

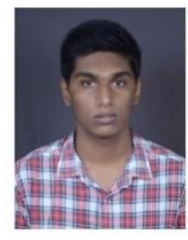

Mr. Abhishek.P.V currently pursuing Bachelor of Engineering in Electrical and Electronics at SDM Institute of Technology, Ujire.

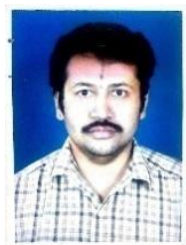

Mr. Sathyanarayana.P is an Assistant professor in Department of Electrical and Electronics Engineering, SDMIT, Ujire. He completed his BE and Mtech in VTU and pursuing $\mathrm{PhD}$ in VTU and his area of interest is renewable energy and power electronics.

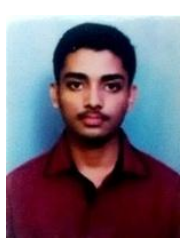

Mr. Sachin.K.Shetty currently pursuing Bachelor of Engineering in Electrical and Electronics at SDM Institute of Technology, Ujire

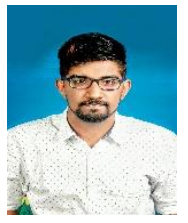

Mr. Srinidhi.M currently pursuing Bachelor of Engineering in Electrical and Electronics at SDM Institute of Technology, Ujire. 